\title{
The Potential Association between the Risk of Post-Surgical Adhesion and the Activated Local Angiotensin II Type 1 Receptors: Need for Novel Treatment Strategies
}

\author{
Mahmood Tavakkoli ${ }^{a}$ Saeed Aali ${ }^{b}$ Borzoo Khaledifarc Gordon A. Ferns ${ }^{d}$ \\ Majid Khazaei ${ }^{\mathrm{e}}$ Kiavash Fekrif ${ }^{\mathrm{f}}$ Mohammad-Hassan Arjmand ${ }^{\mathrm{f}}$ \\ ${ }^{a}$ Kidney Transplantation Complications Research Center, Department of Internal Medicine, Mashhad University \\ of Medical Sciences, Mashhad, Iran; 'bepartment of Urology, Kashani Academic Hospital, Shahrekord University \\ of Medical Sciences, Shahrekord, Iran; 'Department of Surgery, Faculty of Medicine, Shahrekord University of \\ Medical Sciences, Shahrekord, Iran; 'BBighton \& Sussex Medical School, Division of Medical Education, Brighton, UK; \\ eDepartment of Medical Physiology, Faculty of Medicine, Mashhad University of Medical Sciences, Mashhad, Iran; \\ ${ }^{f}$ Cancer Research Center, Shahrekord University of Medical Sciences, Shahrekord, Iran
}

\section{Keywords}

Post-surgical adhesion band · Angiotensin II · Angiotensin type 1 receptor $\cdot$ Inflammation · Oxidative stress · Fibrotic molecules

\begin{abstract}
Background: Post-surgical adhesion bands (PSABs) are a common complication after abdominal or pelvic surgeries for different reasons like cancer treatment. Despite improvements in surgical techniques and the administration of drugs or the use of physical barriers, there has only been limited improvement in the frequency of postoperative adhesions. Complications of PSAB are pain, infertility, intestinal obstruction, and increased mortality. The most important molecular mechanisms for the development of PSAB are inflammatory response, oxidative stress, and overexpression of pro-fibrotic molecules such as transforming growth factor $\beta$. However, questions remain about the pathogenesis of this problem, for example, the causes for individual differences or why cer-
\end{abstract}

karger@karger.com www.karger.com/gat

Karger $\stackrel{\text { ' }}{5}$

BOPEN ACCESS
(C) 2021 The Author(s)

Published by S. Karger AG, Basel

This is an Open Access article licensed under the Creative Commons Attribution-NonCommercial-4.0 International License (CC BY-NC) (http://www.karger.com/Services/OpenAccessLicense), applicable to the online version of the article only. Usage and distribution for commercial purposes requires written permission. tain tissue sites are more prone to post-surgical adhesions. Summary: Addressing the pathological causes of PSAB, the potential role of local angiotensin II/angiotensin II type 1 receptors (Angll/AT1R), may help to prevent this problem. Key Message: The objective of this article was to explore the role of the Angll/AT1R axis potential to induce PSAB and the therapeutic potential of angiotensin receptor blockers in the prevention and treatment of PSAB. @ 2021 The Author(s)

Published by S. Karger AG, Basel

\section{Introduction}

Post-surgical adhesion band (PSAB) formation is a clinical and surgical challenge because it can lead to pain, bowel and fallopian tube obstruction, infertility, and additional therapeutic costs $[1,2]$. PSAB is a common postoperative complication, although the risk of formation of these adhesion bands appears to be increased in patients undergoing abdominal surgery or gynecological pelvic 
operations $[3,4]$. Trauma during surgery, the hypoxia, and infection are the most important etiological factors that are likely to be involved in PSAB [5]. Despite advances in medicine and in surgical techniques, and producing biological barriers such as Seprafilm, PSAB remains a medical challenge and extensive research is necessary.

The renin-angiotensin system (RAS) comprises several peptides that are released into the bloodstream to maintain blood pressure hemostasis and act on target organs. AngII is an octapeptide, with a principal effect on regulating vasoconstriction, inflammation, and fibrosis by interaction with the AngII type 1 receptor (AT1R) [6, 7]. The AT1R is a G-protein-coupled protein that interacts with AngII and mediates the intracellular signaling pathways. It has recently been reported that local RAS components such as AT1R and AngII are expressed in several organs include the gastrointestinal tract, kidney, lung, liver, and other organs. AngII signaling through local AT1R is associated with extracellular matrix (ECM) deposition following enhanced synthesis of proteins in ECM and leads to an increased risk of fibrosis in the liver [6], lung [8] and scar formation in the skin [9]. AngII/AT1R interactions can promote some molecular mechanisms related to fibrosis such as the transforming growth factor $\beta$ (TGF- $\beta$ )/ Smad axis [10], nuclear factor kappa B (NF- $\kappa B$ ) activation, and increased inflammation and oxidative stress (OS) [11, 12]. This review aims to explain some of the molecular mechanisms of the AngII/AT1R axis to induce post-surgical adhesion through the promotion of signaling pathways and pro-fibrotic molecule expression.

\section{Post-Surgical Adhesion Pathogenesis}

Acute inflammation and the recruitment of immune cells and platelet to the injured area after surgery occur in the normal wound healing process; phagocytes cells remove tissue debris and dead cells and release cytokines and chemokines that amplify inflammatory reactions. The proliferation of fibroblasts and myofibroblasts and their migration to the injured area enable them to promote wound closure $[13,14]$. In fibrotic conditions, for example, during post-operative fibrotic band formation, excess immune cell recruitment causes chronic inflammation. A high concentration of inflammatory cytokines and growth factors like TGF- $\beta$ and platelet-derived growth factor occur in chronic inflammation [15]. Experimental animal studies and analysis of adhesion tissues in humans have shown that an imbalance in the expression of cytokines and growth factors is an important factor in the pathogenesis of adhesion formation $[16,17]$. Excessive proliferation and migration of fibroblasts and myofibroblasts in the injured area promote the expression of TGF- $\beta$, which is the most important profibrotic mediator in tissue fibrogenesis [18]. The over-expressed TGF- $\beta$ enhances the expression of collagens and tissue inhibitor of metalloproteinase in ECM and decreases the expression of matrix metalloproteinase (MMPs), and this increases ECM stiffness [19]. Tissue remodeling is an important stage of normal wound healing. The MMPs are involved in maintaining a balance between degradation and accumulation of ECM and help tissue remodeling. The down-regulation of MMPs by TGF- $\beta$ impairs ECM degradation persuade ECM deposition [20]. Also, TGF- $\beta$ can stimulate the expression of plasminogen activator inhibitor-1 (PAI-1) [21]. PAI reduces the fibrinolytic activity by reduction of tissue plasminogen activation (tPA) to help the accumulation of the fibrin gel matrix $[22,23]$. OS is one of the other pathological causes of post-surgical adhesion formation. Hypoxia during the surgery contributes to the migration of immune cells moving toward the hypoxic area, so it leads to the production of reactive oxygen species (ROS) that accelerate inflammation and stimulate adhesion formation [24]. The pathological mechanism related to PSAB is summarized in Figure 1.

\section{Roles of AngII/AT1R in TGF- $\beta$ Signaling}

Recent studies have demonstrated that RAS components such as AT1R and AngII are expressed in different organs, including the gastrointestinal tract [25], liver [26], peritoneum [27], pancreas [28], and other organs. Injuries and trauma to tissues during surgery stimulates an increased expression of AT1R and promotes several molecular signaling pathways related to fibrosis. Paizis et al. showed that after liver injury, a significant expression of local AT1Rs was seen in injured tissue and fibrotic state in the liver [29]. Suekane et al. analyzed colonic stricture tissues from patients with Crohn's disease and found that fibroblasts and fibro-muscular in fibrotic tissues strongly expressed the AT1R [30]. Also in pathological fibrotic cutaneous conditions, there is an increased expression of AngII/ATIRs and TGF- $\beta$ [31]. The TGF- $\beta /$ SMAD signaling pathways are 1 of the most important pathways associated with organ fibrosis that are induced through several mechanisms up-regulated by local AT1Rs. AngII by interaction with AT1R induces the MAPK pathway [32]. The MAPK pathway ERK1/2 or P38 up-regulates downstream profibrotic genes that include TGF- $\beta$. In addition protein kinases, ERK, or P38 stimulated with AngII/ AT1R can phosphorylate and active Smad complex directly to promote fibrotic molecules expression [33]. TGF- $\beta$ is a pro-fibrotic molecule that plays an essential 


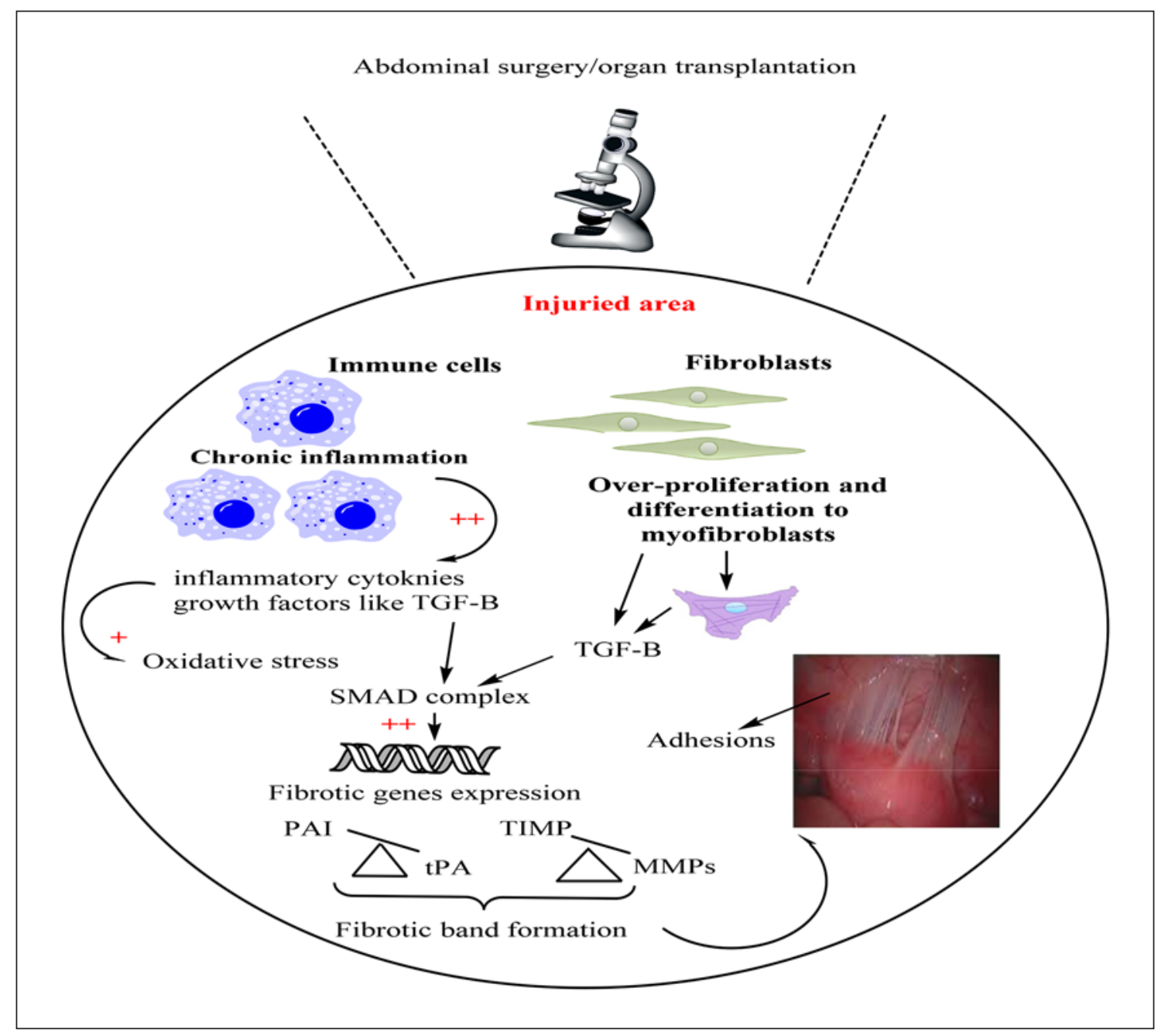

Fig. 1. Pathological reasons for post-surgical adhesion formation after abdominal surgeries or organ transplantation. TGF- $\beta$, transforming growth factor $\beta$; PAI, plasminogen activator inhibitor; PA, tissue plasminogen activation; MMP, matrix metalloproteinase; OS, oxidative stress.

role in the pathology of post-operative adhesion and fibrosis in different organs $[34,35]$. TGF- $\beta$ binds to its receptors and subsequently stimulates the intracellular Smad signaling cascade, enhancing the expression of genes related to fibrotic proteins such as collagen I and $\alpha$-SMA. Moreover, TGF- $\beta$ strongly promotes the differentiation of myofibroblasts and the synthesis of ECM proteins [36]. Besides, TGF- $\beta 1$ inhibits MMPs and the activation of tissue inhibitor metalloproteinase and thereby stimulates ECM deposition and stiffness [37]. Telmisartan, an AT1R antagonist, reduces post-surgical abdominal adhesion by inhibiting the expression of TGF- $\beta$ and collagen [38]. Dinarvand et al. have shown that intraperitoneal administration of Losartan, another AT1R antagonist, reduced postoperative abdominal adhesion through significant changes of serum concentration and mRNA expression of TGF- $\beta$ and PAI- 1 as fibrotic molecules [39]. With respect to the role of AngII/AT1R in the induction of TGF- $\beta / S$ mad signaling pathways to promote fibrosis, AT1R antagonists may have preventive and therapeutic potential to reduce the risk of PSAB in a patient who is due to have surgery. The potential effects of AngII/ AT1R activity in TGF- $\beta /$ Smad signaling are briefed in Figure 2.

\section{Association between AngII/AT1R, Inflammation, and $O S$}

There is a positive feedback between AngII/AT1R and inflammation. Upregulation of AT1R may contribute to an increased expression of molecules related to inflam- 


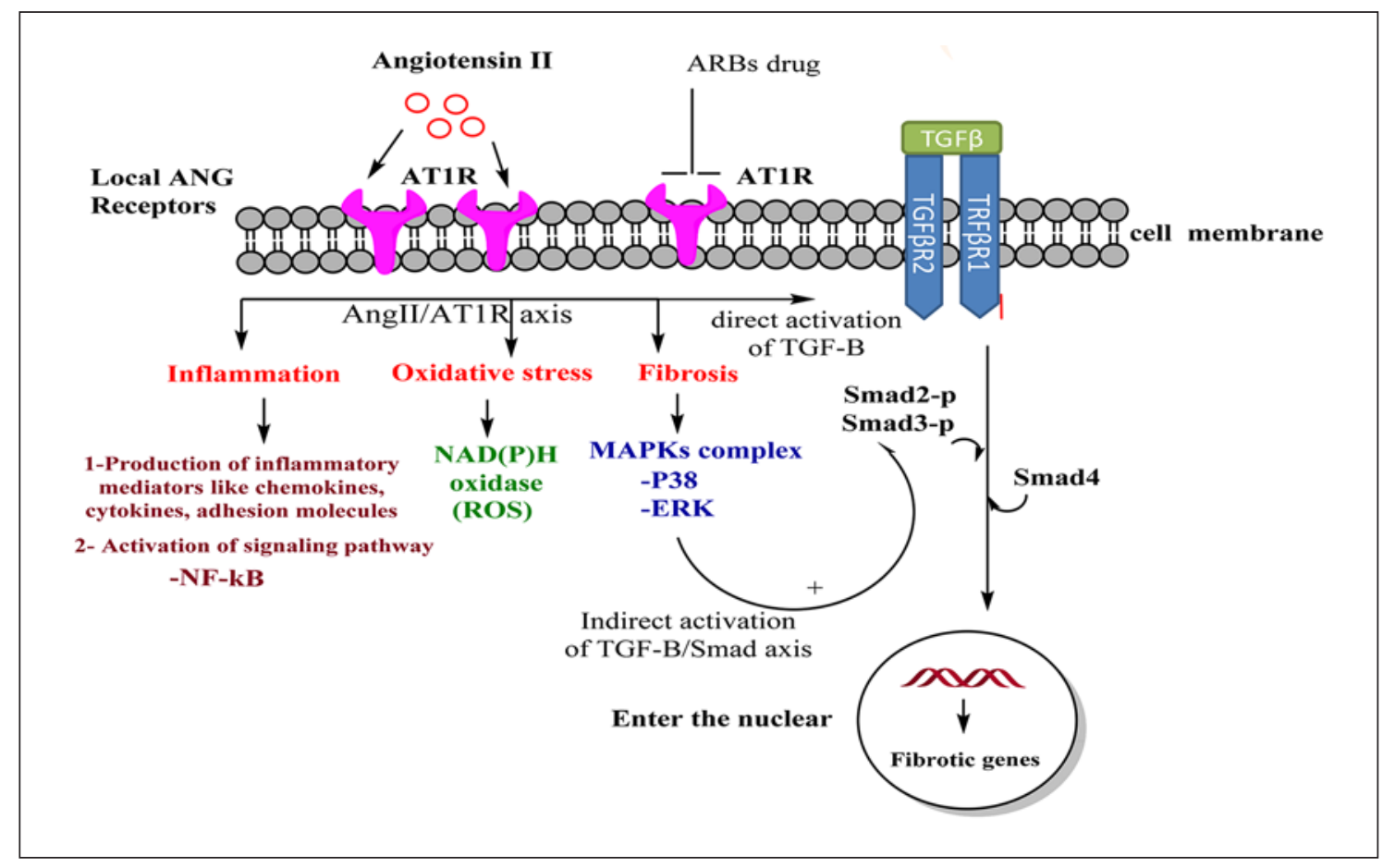

Fig. 2. Effects of AngII on the TGF- $\beta /$ SMAD signaling pathway, inflammation, OS and fibrosis pathway. Binding of ANGII to AT1R, irritate MAPK complex to activate SMAD complex to enter the nucleus and express fibrotic genes. NF-kB activated by AngII/ AT1R interaction increase the expression of molecules related to inflammation. AngII up-regulates the expression of NOX that help

mation and OS [40]; hence, the AT1R promotes inflammation and OS by different molecular mechanisms. Inflammation increases the release of ROS, leading to OS that appears to be an essential process in PSAB and fibrosis. Monocyte chemoattractant protein-1 is an important member of chemokine proteins involved in the processes related to inflammation, and this is up-regulated by AngII through AT1R signaling [41]. Moreover, AT1Rs directly induce NF-kB and its signaling, which leads to producing different inflammatory and adhesive cytokines such as IL6, IL1 $\beta$, TNF- $\alpha$, TGF- $\beta$, ICAM-1, and Eselectin [42]. The AngII/AT1Rs axis can reduce peroxisome proliferator-activated receptors (PPAR $\gamma$ ) which have an anti-inflammatory role [42]. Injuries of the abdominal or pelvic peritoneum during surgery lead to activation of AT1Rs on the surfaces of mesothelial and fibroblasts which induce inflammatory and adhesive molecules to stimulate PSAB in the peritoneal or pelvic cavity [43]. We found that the intra-peritoneal administration of telmisartan after abdominal surgery in a rat model significantly reduced the expression of the inflam- to increase of OS. These pathological conditions are parallel with adhesion formation post-surgical pathogenesis. NF-kB, nuclear factor kappa $\mathrm{B}$; TGF- $\beta$, transforming growth factor $\beta$; OS, oxidative stress; NOX, NADH oxidase; AngII/AT1R angiotensin II/angiotensin II type 1 receptor; ROS, reactive oxygen species.

matory cytokines TNF- $\alpha$ and IL6 through AT1Rs inhibition [38]. After tissue injuries, the accumulation of immune cells and fibroblasts in the injured area can stimulate the NF-kB signaling pathway to increase inflammatory cytokines such as TNF- $\alpha$ and promote the formation of ROS [44]. Through the release of ROS, the AngII/AT1R pathway may reduce nitric oxide synthesis and activate NF-kB indirectly. OS is a potential regulator in the pathogenesis of PSAB. OS is associated with the release of increased levels of ROS that include superoxide, hydrogen peroxide, and hydroxyl radical, with impaired activity of the antioxidant system. NOXs (NADH oxidase) are a group of enzymes to produce ROS localized in different tissues that catalyze the conversion of oxygen to superoxide molecule $\left(\mathrm{O}_{2}^{-}\right)$to increase OS [4548]. Interaction of AT1R with activation of AngII causes molecular mechanisms to lead to the stimulating of NOX isoforms to produce ROS and OS. One study showed that AngII with AT1R stimulation causes NOX isoform activation in hepatic stellate cells, and induce OS, leading to liver fibrosis [49]. In unilateral ureteral obstruction and 
Table 1. Key points of AngII/AT1R effects in the pathogenesis of PSAB.

AngII/AT1R axis effects

TGF- $\beta$ /Smad signaling

Stimulation of MAPK complex signaling pathways by AngII/AT1R leads to both TGF- $\beta$ gene expression directly and active the phosphorylation of Smad2/3 to upregulate genes such as TIMP and PAI related to fibrotic conditions like PSAB

Inflammation and oxidative stress
AT1Rs directly induce NF- $\kappa$ B signaling pathways which lead to producing different inflammatory and adhesive cytokines such as IL6, IL1 $\beta$, TNF- $\alpha$, TGF- $\beta$, and ICAM- 1 that are important in PASB pathogenesis. Increase inflammatory cytokines such as TNF- $\alpha$ promote the formation of ROS. Also, AngII/AT1R interaction causes molecular mechanisms to lead to the stimulating of NOX isoforms to produce ROS and OS

Fibrotic molecules expression expression that is a fibrotic molecule and important in PSAB pathogenesis. Also, a-SMA important molecules in fibrosis are promoted by AngII/AT1R axis

a-SMA, $\alpha$-smooth muscle actin; PSAB, post-surgical adhesion band; PAI, plasminogen activator inhibitor; NF-kB, nuclear factor kappa B; TGF- $\beta$, transforming growth factor $\beta$; ROS, reactive oxygen species; OS, oxidative stress; NOX, NADH oxidase; AngII/AT1R, angiotensin II/angiotensin II type 1 receptor.

fibrosis, AT1Rs were increased and may stimulate the expression of NOX isoforms to induce OS and inflammation related to fibrosis; Kim et al. [50] showed that fimasartan treatment leads to the down-regulation of NOX and OS level by AT1Rs inhibition. Other studies have indicated that blocking AngII binding to AT1 receptors can reduce superoxide generation by reducing molecular mechanisms related to inflammation and NOX expression, thus reducing OS. Potential effects of AT1R on signaling pathways related to inflammation and OS are summarized in Figure 2.

\section{AngII/AT1R and Fibrotic Molecules Expression}

Fibrinolytic activity after trauma in tissues such as the peritoneal layer after peritoneal or pelvic surgeries is an essential activity for tissue remodeling and the wound healing process [51]. Two molecules associated with fibrinolysis activity are $\mathrm{PA}$ and PAI, and the balance between these molecules is necessary for a normal wound healing process, but in PSAB, an imbalance between $\mathrm{PA}$ and PAI toward PAI expression inhibits fibrinolytic activity and induces fibrinogenesis, thereby increasing the risk of PSAB [52]. PAI is a protease inhibitor that inhibits the tPA activity, reduces the fibrinolytic action of cells, and increases the risk of fibrin gel matrix accumulation and fibrosis [53, 54]. The up-regulation of AngII/AT1Rs increases the expression of PAI by different molecular mechanisms. PAI expression is regulated by the TGF- $\beta /$ Smad signaling pathways [55]. AngII/AT1Rs leads to activation of p38 MAPK and c-Jun N-terminal kinases, and contributes to the TGF- $\beta /$ Smad signaling pathway that is a regulator for PAI expression $[32,55]$. Moreover, AngII can stimulate PAI expression through TNF- $\alpha$; Takeshita et al. [56] have shown that local up-regulated AngII/ AT1Rs stimulate PAI-1 production in vitro in human hepatic hepatocytes cell line and found that angiotensin AT1 receptor antagonists inhibit TNF- $\alpha$ mediated expression of PAI-1. Rosella et al. [57] have demonstrated that Losartan can reduce PAI expression and PAI level in rat nonalcoholic fatty liver disease model.

One of the other fibrotic molecules involved in the pathogenesis of PSAB is $\alpha$-smooth muscle actin ( $\alpha$-SMA) (actin alpha 2). $\alpha$-SMA is a marker for fibrogenic activity produced by fibroblast and myofibroblasts, key cells in organ fibrogenesis, overexpressed in PSAB [58]. Some studies have been focused on the role of AngII in the regulation of a-SMA expression. In vitro experiments in cardiomyocytes showed that AngII up-regulate the expression a-SMA that promotes cardiac hypertrophy [59]. Kurikawa et al. [60] have reported that AT1R expression is up-regulated in the fibrotic area of the liver and hepatic stellate cells increase the mRNA expression of collagen I and $\alpha$-SMA, and they found that olmesartan, an antagonist of AT1R, decreases the expression of fibrotic molecules collagen I and $\alpha$-SMA, and improves liver fibrosis. Because of the roles of AngII/AT1R signaling to stimulate profibrotic molecules expression, AT1R blockers may be considered to be novel therapies in the prevention of fibrogenesis. The roles of AngII/AT1R in cancer progression are summarized in Table 1. 
Therapeutic Potential of Angiotensin Receptor

Blockers in PSAB

Angiotensin receptor blockers (ARBs) are a group of drugs that usually are administrated for the treatment of hypertension in the clinic. Besides the anti-hypertensive effects of ARBs, recent studies have demonstrated that these drugs have the potential to reduce inflammation, OS, and fibrosis in different organs. These findings provided new insights that this family can have the potential to prevent or reduce post-surgical adhesion. Arjmand et al. [38] have shown that telmisartan could significantly decrease post-surgical fibrotic bands in comparison with the control group in the rat model. They found that telmisartan was able to reduce inflammatory mediators such as IL6, TNF- $\alpha$, and TGF- $\beta$; also, the OS index was decreased and anti-oxidant capacity was increased. Moreover, they showed that the expression of fibrotic genes collagen 1 and 3 was significantly decreased in the group of treatment with telmisartan [38]. Dinarvand et al. [39] have demonstrated that Losartan decreases post-surgical adhesion in the mouse model. Intraperitoneal administration of losartan significantly decreased fibrotic bands after the adhesion induction model. They founded that Losartan was able to reduce both TGF- $\beta$ and PAI- 1 concentration in serum and mRNA expression in peritoneal tissues. More results observed that serum concentrations of tPA and its mRNA level in peritoneal tissues were increased in animals that received losartan [39]. In other studies, candesartan can reduce adhesion formation using an experimental model of peritoneal adhesions; candesartan can decrease the severity of adhesion formation using an experimental model of peritoneal adhesions in the rat. Tokinaga et al. [61] found that intraperitoneal administration of candesartan reduces PAI-1 mRNA expression in injured tissues and was able to reduce the adhesion score. These findings suggested that using these drugs in patients for surgeries may have the potential to prevent post-surgical adhesion.

\section{Conclusion}

We provided a novel insight into the molecular mechanisms by which activated local AngII/AT1Rs after surgery may increase the risk of PSAB and fibrogenesis. This review article was focused on molecular mechanism of AngII/AT1R in increasing the expression of TGF- $\beta$, and other fibrotic molecules followed it, development of inflammation, and OS that these molecular events facilitate the formation of fibrotic bands post-operative. Based on the pathological role of local AngII/AT1R signaling after special abdominal or pelvic surgeries, the administration of ARBs may be considered as a new and efficient therapy to prevent postsurgical adhesions. More (pre-)clinical researches should be performed to receive better information on the clinical significance of ARBs against PSAB formation during urological, abdominal, or pelvic surgeries.

\section{Conflict of Interest Statement}

The authors have no conflict of interest to disclose.

\section{Funding Sources}

The authors did not receive any funding.

\section{Author Contributions}

Mahmood Tvavakkoli, Saied Aali, and Kiavash Fekri interpreted data for the work; Gordon A Ferns revised the manuscript for intellectual contents; Mohammad-Hassan Arjmand designed the work and approved the final version to be published.

\section{References}

1 Sulaiman H, Gabella G, Davis C, Mutsaers SE, Boulos P, Laurent GJ, et al. Growth of nerve fibres into murine peritoneal adhesions. J Pathol. 2000;192(3):396-403.

2 Parker M, Wilson MS, Menzies D, Sunderland G, Clark D, Knight A, et al. The SCAR-3 study: 5-year adhesion-related readmission risk following lower abdominal surgical procedures. Colorectal disease. 2005;7(6):551-8.
3 Liakakos T, Thomakos N, Fine PM, Dervenis C, Young RL. Peritoneal adhesions: etiology, pathophysiology, and clinical significance. Digestive surgery. 2001;18(4):260-73.

4 Menzies $\mathrm{D}$, Ellis $\mathrm{H}$. Intestinal obstruction from adhesions-how big is the problem? Ann R Coll Surg Engl. 1990;72(1):60.

5 Maciver AH, McCall M, James Shapiro AM. Intra-abdominal adhesions: cellular mechanisms and strategies for prevention. Int $J$ Surg. 2011;9(8):589-94.
6 Shim KY, Eom YW, Kim MY, Kang SH, Baik SK. Role of the renin-angiotensin system in hepatic fibrosis and portal hypertension. Korean J Intern Med. 2018;33(3):453.

7 Lavoie JL, Sigmund CD. Minireview: overview of the renin-angiotensin system - an endocrine and paracrine system. Endocrinology. 2003;144(6):2179-83.
Tavakkoli/Aali/Khaledifar/Ferns/Khazaei/ Fekri/Arjmand 
8 Uhal BD, Li X, Piasecki CC, Molina-Molina $\mathrm{M}$. Angiotensin signalling in pulmonary fibrosis. Int J Biochem Cell Biol. 2012;44(3): $465-8$.

9 Huang C, Ogawa R. The link between hypertension and pathological scarring: does hypertension cause or promote keloid and hypertrophic scar pathogenesis?. Wound Repair Regen. 2014;22(4):462-6.

10 Rosenkranz S. TGF-betal and angiotensin networking in cardiac remodeling. Cardiovasc Res. 2004;63(3):423-32.

11 Ruiz-Ortega M, Lorenzo O, Suzuki Y, Rupérez M, Egido J. Proinflammatory actions of angiotensins. Curr Opin Nephrol Hypertens. 2001;10(3):321-9.

12 Dikalova A, Clempus R, Lassègue B, Cheng G, McCoy J, Dikalov S, et al. NOX1 overexpression potentiates angiotensin II-induced hypertension and vascular smooth muscle hypertrophy in transgenic mice. Circulation. 2005;112(17):2668-76.

13 Velnar T, Bailey T, Smrkolj V. The wound healing process: an overview of the cellular and molecular mechanisms. J Int Med Res. 2009;37(5):1528-42.

14 Li B, Wang JH. Fibroblasts and myofibroblasts in wound healing: force generation and measurement. J Tissue Viability. 2011;20(4): $108-20$.

15 López-Novoa JM, Nieto MA. Inflammation and EMT: an alliance towards organ fibrosis and cancer progression. EMBO molecular medicine. 2009;1(6--7):303-14.

16 Van Rossen ME, Hofland LJ, Van den Tol MP, Van Koetsveld PM, Jeekel J, Marquet RL, et al. Effect of inflammatory cytokines and growth factors on tumour cell adhesion to the peritoneum. J Pathol. 2001;193(4):530-7.

17 Cheong YC, Laird SM, Shelton JB, Ledger WL, Li TC, Cooke ID. The correlation of adhesions and peritoneal fluid cytokine concentrations: a pilot study. Hum Reprod. 2002; 17(4):1039-45.

18 Kim L, Kim DK, Yang WI, Shin DH, Jung IM, Park HK, et al. Overexpression of transforming growth factor-beta 1 in the valvular fibrosis of chronic rheumatic heart disease. J Korean Med Sci. 2008;23(1):41-8.

19 Khanna A, Plummer M, Bromberek C, Bresnahan B, Hariharan S. Expression of TGF-beta and fibrogenic genes in transplant recipients with tacrolimus and cyclosporine nephrotoxicity. Kidney Int. 2002;62(6):2257-63.

20 Vaze M, Joshi C, Patil D. Molecular basis of post-surgical peritoneal adhesions-an overview. Veterinary World. 2010;3(22).

21 Samarakoon R, Overstreet JM, Higgins SP, Higgins PJ. TGF- $\beta 1 \rightarrow$ SMAD/p53/USF2 $\rightarrow$ PAI-1 transcriptional axis in ureteral obstruction-induced renal fibrosis. Cell Tissue Res. 2012;347(1):117-28.

22 Saed GM, Diamond MP. Molecular characterization of postoperative adhesions: the adhesion phenotype. J Am Assoc Gynecol Laparosc. 2004;11(3):307-14.
23 Faber DR, De Groot PG, Visseren FL. Role of adipose tissue in haemostasis, coagulation and fibrinolysis. Obes Rev. 2009;10(5):55463.

24 Awonuga AO, Belotte J, Abuanzeh S, Fletcher NM, Diamond MP, Saed GM. Advances in the pathogenesis of adhesion development: the role of oxidative stress. Reprod Sci. 2014; 21(7):823-36

25 BY S, Jardé T, McCarthy A, Ashworth A, De Leng WW, Offerhaus GJA, et al. Intestinal renin-angiotensin system is stimulated after deletion of Lkb1. Gut. 2012;61(2):202-13.

26 Yaguchi S, Ogawa Y, Shimmura S, Kawakita T, Hatou S, Satofuka S, et al. Angiotensin II type 1 receptor antagonist attenuates lacrimal gland, lung, and liver fibrosis in a murine model of chronic graft-versus-host disease. PLos One. 2013;8(6):e64724.

27 Morinelli TA, Luttrell LM, Strungs EG, Ullian ME. Angiotensin II receptors and peritoneal dialysis-induced peritoneal fibrosis. Int J Biochem Cell Biol. 2016;77(Pt B):240-50.

28 Tahmasebi M, Puddefoot JR, Inwang ER, Vinson GP. The tissue renin-angiotensin system in human pancreas. J Endocrinol. 1999; 161(2):317-22.

29 Paizis G, Cooper ME, Schembri JM, Tikellis C, Burrell LM, Angus PW. Up-regulation of components of the renin-angiotensin system in the bile duct-ligated rat liver. Gastroenterology. 2002;123(5):1667-76.

30 Suekane T, Ikura Y, Watanabe K, Arimoto J, Iwasa $\mathrm{Y}$, Sugama $\mathrm{Y}$, et al. Phenotypic change and accumulation of smooth muscle cells in strictures in Crohn's disease: relevance to local angiotensin II system. J Gastroenterol. 2010;45(8):821-30.

31 Kawaguchi Y, Takagi K, Hara M, Fukasawa C, Sugiura T, Nishimagi E, et al. Angiotensin II in the lesional skin of systemic sclerosis patients contributes to tissue fibrosis via angiotensin II type 1 receptors. Arthritis Rheum. 2004;50(1):216-26.

32 Xie JY, Chen N, Ren H, Wang WM. Angiotensin II-mediated activation of fibrotic pathways through ERK1/2 in rat peritoneal mesothelial cells. Ren Fail. 2010;32(7):871-9.

33 Murphy AM, Wong AL, Bezuhly M. Modulation of angiotensin II signaling in the prevention of fibrosis. Fibrogenesis Tissue Repair. 2015;8:7.

34 Chegini N. TGF-beta system: the principal profibrotic mediator of peritoneal adhesion formation. Semin Reprod Med. 2008;26(4): 298-312.

35 Pohlers D, Brenmoehl J, Löffler I, Müller CK, Leipner C, Schultze-Mosgau S, et al. TGF-beta and fibrosis in different organs-molecular pathway imprints. Biochim Biophys Acta. 2009;1792(8):746-56.

36 Rao B, Malathi N, Narashiman S, Rajan ST. Evaluation of myofibroblasts by expression of alpha smooth muscle actin: a marker in fibrosis, dysplasia and carcinoma. J Clin Diagn Res. 2014;8(4):ZC14.
37 Mauviel A. Transforming growth factor-beta: a key mediator of fibrosis. Methods Mol Med. 2005;117:69-80.

38 Arjmand M-H, Zahedi-Avval F, Barneh F, Mousavi SH, Asgharzadeh F, Hashemzehi M, et al. Intraperitoneal Administration of Telmisartan Prevents Postsurgical Adhesion Band Formation. J Surg Res. 2020;248:171-81.

39 Dinarvand P, Farhadian S, Seyedjafari E, Shafiee A, Jalali A, Sanaei-Rad P, et al. Novel approach to reduce postsurgical adhesions to a minimum: administration of losartan plus atorvastatin intraperitoneally. J Surg Res. 2013;181(1):91-8.

40 Wang X, Khaidakov M, Ding Z, Mitra S, Lu J, Liu S, et al. Cross-talk between inflammation and angiotensin II: studies based on direct transfection of cardiomyocytes with AT1R and AT2R cDNA. Exp Biol Med. 2012; 237(12):1394-401.

41 Kato S, Luyckx VA, Ots M, Lee KW, Ziai F, Troy JL, et al. Renin-angiotensin blockade lowers MCP-1 expression in diabetic rats. Kidney Int. 1999;56(3):1037-48.

42 Tham DM, Martin-McNulty B, Wang YX, Wilson DW, Vergona R, Sullivan ME, et al. Angiotensin II is associated with activation of NF-kappaB-mediated genes and downregulation of PPARs. Physiol Genomics. 2002;11(1): 21-30.

43 Jayne D. Molecular biology of peritoneal carcinomatosis. Peritoneal Carcinomatosis. Springer; 2007. p. 21-33.

44 Yamamoto Y, Gaynor RB. Therapeutic potential of inhibition of the NF-kappaB pathway in the treatment of inflammation and cancer. J Clin Invest. 2001;107(2):135-42.

45 Griendling KK, Sorescu D, Lassègue B, UshioFukai M. Modulation of protein kinase activity and gene expression by reactive oxygen species and their role in vascular physiology and pathophysiology. Arterioscler Thromb Vasc Biol. 2000;20(10):2175-83.

46 Xiao L, Pimentel DR, Wang J, Singh K, Colucci WS, Sawyer DB. Role of reactive oxygen species and NAD (P) $\mathrm{H}$ oxidase in a1adrenoceptor signaling in adult rat cardiac myocytes. Am J Physiol Cell Physiol. 2002; 282(4):C926-C34.

47 Gill PS, Wilcox CS. NADPH oxidases in the kidney. Antioxid Redox Signal. 2006;8(9-10): 1597-607.

48 Brandes RP, Kreuzer J. Vascular NADPH oxidases: molecular mechanisms of activation. Cardiovasc Res. 2005;65(1):16-27.

49 Bataller R, Schwabe RF, Choi YH, Yang L, Paik YH, Lindquist J, et al. NADPH oxidase signal transduces angiotensin II in hepatic stellate cells and is critical in hepatic fibrosis. J Clin Invest. 2003;112(9):1383-94.

50 Kim S, Kim SJ, Yoon HE, Chung S, Choi BS, Park CW, et al. Fimasartan, a Novel Angiotensin-Receptor Blocker, Protects against Renal Inflammation and Fibrosis in Mice with Unilateral Ureteral Obstruction: the Possible Role of Nrf2. Int J Med Sci. 2015;12(11):891-904. 
51 Bae WJ, Yi JK, Park J, Kang SK, Jang JH, Kim EC. Lysyl oxidase-mediated VEGF-induced differentiation and angiogenesis in human dental pulp cells. Int Endod J. 2018;51(3): 335-46.

52 Ince A, Eroglu A, Tarhan O, Bülbül M. Peritoneal fibrinolytic activity in peritonitis. Am J Surg. 2002;183(1):67-9.

53 Rerolle JP, Hertig A, Nguyen G, Sraer JD, Rondeau EP. Plasminogen activator inhibitor type 1 is a potential target in renal fibrogenesis. Kidney Int. 2000;58(5):1841-50.

54 Mercer PF, Chambers RC. Coagulation and coagulation signalling in fibrosis. Biochim Biophys Acta. 2013;1832(7):1018-27.

55 Vayalil PK, Iles KE, Choi J, Yi AK, Postlethwait EM, Liu RM. Glutathione suppresses TGF-beta-induced PAI-1 expression by inhibiting p38 and JNK MAPK and the binding of AP-1, SP-1, and Smad to the PAI-1 promoter. Am J Physiol Lung Cell Mol Physiol. 2007;293(5):L1281-92.
56 Takeshita Y, Takamura T, Ando H, Hamaguchi E, Takazakura A, Matsuzawa-Nagata N, et al. Cross talk of tumor necrosis factor- $\alpha$ and the renin-angiotensin system in tumor necrosis factor- $\alpha$-induced plasminogen activator inhibitor-1 production from hepatocytes. Eur J Pharmacol. 2008;579(1-3):426-32.

57 Rosselli MS, Burgueño AL, Carabelli J, Schuman M, Pirola CJ, Sookoian S. Losartan reduces liver expression of plasminogen activator inhibitor-1 (PAI-1) in a high fat-induced rat nonalcoholic fatty liver disease model. Atherosclerosis. 2009;206(1):119-26.

58 Saed GM, Diamond MP. Differential expression of alpha smooth muscle cell actin in human fibroblasts isolated from intraperitoneal adhesions and normal peritoneal tissues. Fertil Steril. 2004;82 Suppl 3:1188-92.
59 Clément S, Pellieux C, Chaponnier C, Pedrazzini T, Gabbiani G. Angiotensin II stimulates alpha-skeletal actin expression in cadiomyocytes in vitro and in vivo in the absence of hypertension. Differentiation. 2001;69(1): 66-74.

60 Kurikawa N, Suga M, Kuroda S, Yamada K, Ishikawa $\mathrm{H}$. An angiotensin II type 1 receptor antagonist, olmesartan medoxomil, improves experimental liver fibrosis by suppression of proliferation and collagen synthesis in activated hepatic stellate cells. Br J Pharmacol. 2003;139(6):1085-94.

61 Tokinaga Y, Kimoto Y, Tange K, Ogawa K, Hatano Y. Reduction mechanism of adhesion formation by an angiotensin type 1 receptor antagonist. Langenbecks Arch Surg. 2011 Jan; 396(1):127-32. 